\title{
Decision support system for emergency management of oil spill accidents in the Mediterranean Sea
}

\author{
Svitlana Liubartseva ${ }^{1}$, Giovanni Coppini ${ }^{2}$, Nadia Pinardi ${ }^{3}$, Michela De Dominicis ${ }^{4,5}$, Rita Lecci ${ }^{2}$, Giuseppe Turrisi ${ }^{2}$, \\ Sergio Cretì ${ }^{2}$, Sara Martinelli ${ }^{2}$, Paola Agostini ${ }^{2}$, Palmalisa Marra ${ }^{6}$, and Francesco Palermo ${ }^{2}$ \\ ${ }^{1}$ Fondazione CMCC - Centro Euro-Mediterraneo sui Cambiamenti Climatici, via M. Franceschini 31, 40128 Bologna, Italy \\ ${ }^{2}$ Fondazione CMCC - Centro Euro-Mediterraneo sui Cambiamenti Climatici, via Augusto Imperatore 16, 73100 Lecce, Italy \\ ${ }^{3}$ Dipartimento di Fisica e Astronomia (DIFA) Università degli Studi di Bologna, viale Berti-Pichat 6/2, 40127 Bologna, Italy \\ ${ }^{4}$ Istituto Nazionale di Geofisica e Vulcanologia, via D. Creti 12, 40128 Bologna, Italy \\ ${ }^{5}$ National Oceanography Centre, 6 Brownlow Street, Liverpool, Merseyside, L3 5DA, UK \\ ${ }^{6}$ Links Management and Technology S.p.A. - via R. Scotellaro 55, 73100 Lecce, Italy
}

Correspondence to: Svitlana Liubartseva (svitlana.liubartseva@cmcc.it)

Received: 15 May 2016 - Published in Nat. Hazards Earth Syst. Sci. Discuss.: 7 June 2016

Accepted: 4 August 2016 - Published: 30 August 2016

\begin{abstract}
This paper presents an innovative web-based decision support system to facilitate emergency management in the case of oil spill accidents, called WITOIL (Where Is The Oil). The system can be applied to create a forecast of oil spill events, evaluate uncertainty of the predictions, and calculate hazards based on historical meteo-oceanographic datasets. To compute the oil transport and transformation, WITOIL uses the MEDSLIK-II oil spill model forced by operational meteo-oceanographic services. Results of the modeling are visualized through Google Maps. A special application for Android is designed to provide mobile access for competent authorities, technical and scientific institutions, and citizens.
\end{abstract}

\section{Introduction}

Possible oil spill accidents and operational pollution could have severe impacts on the Mediterranean Basin. It is therefore crucial to provide decision makers, stakeholders, and the public with a trustworthy DSS (Decision Support System) able to maintain the highest quality and near-real-time information during oil pollution response.

A new generation of DSS and similar systems is based on environmental monitoring, state-of-the-art modeling, and innovative technology platforms. All of them incorporate the oil spill model as a forecasting tool driven by oceanographic and atmospheric datasets. A powerful data visual- ization module efficiently provides service delivery. Some types of DSS are connected with environmental databases, evaluating the impact on the population and the ecosystem. Recently, several systems have been set up and developed. An oil trajectory forecasting tool GNOME (Zelenke et al., 2012) and an oil weathering model ADIOS (Lehr et al., 2002) were combined with Environmental Sensitivity Index maps (Jensen et al., 1990) and a fine-resolution visualization module ERMA (ERMA, 2014) for efficient spill response planning (Muskat, 2014). At the European level, four oil spill models were integrated in the framework of the MEDESS4MS project (Mediterranean Decision Support System for Marine Safety) as follows: MOTHY (Daniel, 1996), MEDSLIK (Zodiatis et al., 2008), MEDSLIK-II (De Dominicis et al., 2013a), and POSEIDON-OSM (Nittis et al., 2006). Using unified data flows, they were incorporated into a multi-model network to provide a round-theclock forecast of oil spills. A similar combination of various global and regional meteo-oceanographic forecasting systems with the MOHID oil spill model (Carracedo et al., 2006) was conducted by Fernandes et al. (2013). Fusion of the SINTEF OSCAR oil spill model (Reed et al., 1995) with an environmental geographical information system (GIS) dataset resulted in the creation of a DSS focused on the estimation of economic and ecological impact (Wirtz and Liu, 2006). The system was applied to evaluate the shortand mid-term consequences of the Prestige case (Spain, 
November 2002). A combination of SAR (synthetic aperture radar) imagery, aerial surveillance, and oil spill modeling by Seatrack Web (Ambjorn, 2007) was used to make appropriate decisions on oil combating activities in the Baltic and North seas (Anderson et al., 2010).

An up-to-date DSS requires not only the oil spill forecast but also the evaluation of uncertainty of such a forecast, which is critical for timely, efficient, and cost-effective response and recovery. Uncertainty in the prediction of the oil transport and transformation stems from the uncertain environment and the sparse data. In contrast to atmospheric pollution models (e.g., Bergin et al., 1999), the methods of uncertainty quantification are not well established in oil spill modeling. Nevertheless, uncertainty algorithms with respect to perturbation of ocean currents and wind were implemented in General NOAA Operational Modeling Environment (GNOME) (Zelenke et al., 2012). Currently, the majority of uncertainty estimations still remain a matter of research, being beyond the scope of web-based operational implementations. For example, Sebastiao and Guedes Soares (2007) varied the current and wind components, wind drag coefficient, and deflection angle for the Aragon case (Portugal, December 1989). Uncertainty analysis with respect to amount of spilled oil was carried out in Xu et al. (2012). A multi-model approach which used an ensemble of meteooceanographic models was implemented in De Dominicis et al. (2014), which allowed the authors to improve the quality of oil drift prediction significantly.

In the present work, the WITOIL (Where Is The Oil) DSS (http://www.witoil.com) has been developed as a part of TESSA project (Development of Technologies for Situational Sea Awareness) portfolio. The project aimed to strengthen the operational oceanography service in southern Italy and integrate it with information platforms for delivering data on situational sea awareness. WITOIL is tailored to the needs of managing emergency situations and supporting the decision-making process in response operations.

The distinct features of WITOIL include (1) a threemodule structure, embracing the oil spill forecast, uncertainty evaluation, and hazard assessment; (2) the Lagrangian oil spill model MEDSLIK-II, coupled with basin-scale and regional operational meteo-oceanographic services; (3) webbased applications for different devices, including personal computers, tablets, and mobile phones etc.; and (4) the visualization of geospatial information by means of Google Maps.

The paper is organized as follows: in Sect. 2, the oil spill model and meteo-oceanographic data are presented; Sect. 3 describes the structure and main components of DSS; and Sects. 4 and 5 contain the results and conclusions, respectively.

\section{Models and data}

\subsection{The oil spill model MEDSLIK-II}

The oil spill model code MEDSLIK-II (De Dominicis et al., $2013 \mathrm{a}, \mathrm{b}$ ) is a freely available community model ${ }^{1}$. It is used to predict the transport and oil transformation due to complex physical processes occurring at the sea surface.

MEDSLIK-II calculates the advection-diffusion processes using a Lagrangian approach. The oil slick is discretized into constituent particles. Each particle moves due to currents, wind, and waves, data on which are provided by external basin-scale or regional oceanographic and atmospheric models.

The oil transformation processes at the surface are calculated by means of bulk formulas that describe the changes in the surface oil volume due to three main processes, known collectively as weathering (evaporation, dispersion, and spreading). Formation of water-in-oil emulsion is also taken into consideration. If an oil particle arrives on the coast, the model is able to simulate the adsorption of particles into the coastal environment, taking into account the probability that oil may be washed back into the water.

As outputs, MEDSLIK-II provides the oil concentrations at the surface, in the dispersed water-column fraction, and on the coast. Mass balance components of the oil are calculated as a function of time, which allows temporal tracking of oil weathering.

\subsection{Meteo-oceanographic data}

As detailed above, MEDSLIK-II requires the input of data about sea currents, sea surface temperatures, and atmospheric wind.

The ocean current data and sea surface temperature are provided by hourly forecast and daily analysis fields produced by the Mediterranean Forecasting System (MFS) from the Copernicus Marine Environment Monitoring Service $\left(\mathrm{CMEMS}^{2}\right)$, Mediterranean Monitoring and Forecasting Centre Med-MFC; and by hourly forecast and daily simulation fields generated by the Adriatic Forecasting System $\left(\mathrm{AFS}^{3}\right)$.

Covering the entire Mediterranean Sea with some extension into the Atlantic, MFS provides oceanographic data at $1 / 16^{\circ} \times 1 / 16^{\circ}$ horizontal resolution and 71 unevenly spaced vertical levels (Pinardi et al., 2003; Tonani et al., 2008). The analyses are produced by a data assimilation system that uses satellite and in situ data (Dobricic and Pinardi, 2008).

The Adriatic Forecasting System (Oddo et al., 2009) encompasses the whole Adriatic basin and extends southward of the Strait of Otranto into the northern Ionian Sea (39.0$\left.45.8^{\circ} \mathrm{N}, 12.2-20.8^{\circ} \mathrm{E}\right)$. The system is implemented at the

\footnotetext{
${ }^{1}$ http://medslikii.bo.ingv.it

${ }^{2} \mathrm{http}: / /$ marine.copernicus.eu

${ }^{3}$ http://oceanlab.cmcc.it/afs
} 
horizontal resolution of $1 / 45^{\circ} \times 1 / 45^{\circ}$ and 31 sigma layers in the vertical. The lateral boundary conditions for the sea current velocity, temperature, and salinity are imposed from MFS on a daily basis.

The atmospheric wind data are provided by the European Centre for Medium-Range Weather Forecasts (ECMWF) forecasts and analyses, at $0.125^{\circ}$ horizontal and $6 \mathrm{~h}$ temporal resolution.

\section{Structure and main components of the WITOIL DSS}

Decision support system WITOIL consists of a client part and server component (Fig. 1). The client part is presented by a GUI (graphical user interface) to configure and trigger the system, as well as to visualize the results using Google Maps.

The server component includes three modules as follows:

- an oil spill forecasting module to provide the prediction of the oil trajectory and fate on a near-real-time basis;

- an uncertainty module aimed at on-the-fly estimation of forecast uncertainty; and

- a hazard module for mapping the probability of pollution from possible oil spill accidents on a long-term basis.

The server component incorporates MEDSLIK-II and meteooceanographic data sources described above. Hazard module uses precalculated MEDSLIK-II outputs based on hypothetical oil spill scenarios and historical variability of the marine environment simulated by the meteo-oceanographic models.

\subsection{Oil spill forecasting module}

The oil spill forecasting module provides a resilient 24/7 operational service, supporting both basic and advanced use. In the basic mode, the system runs the oil spill scenarios according to the initial information about the starting spill position and date, type of the oil, the oil volume or spill rate and duration, simulation length (the time period of tracking the oil spill), and time step (output interval). Necessary oceanographic and atmospheric data can be chosen from a set of available model outputs.

To calculate the Stokes drift, the latest version of WITOIL uses the empirical, so-called JONSWAP wave spectrum as a function of wind speed and fetch (Hasselmann et al., 1973). Recently, De Dominicis et al. (2016) have modified MEDSLIK-II for the direct usage of wave model outputs, which is more accurate and computationally efficient than JONSWAP parameterization. This important option will be adapted in the next version of WITOIL.

Advanced use of WITOIL requires users who are experienced in oil spill modeling to set up advanced parameters

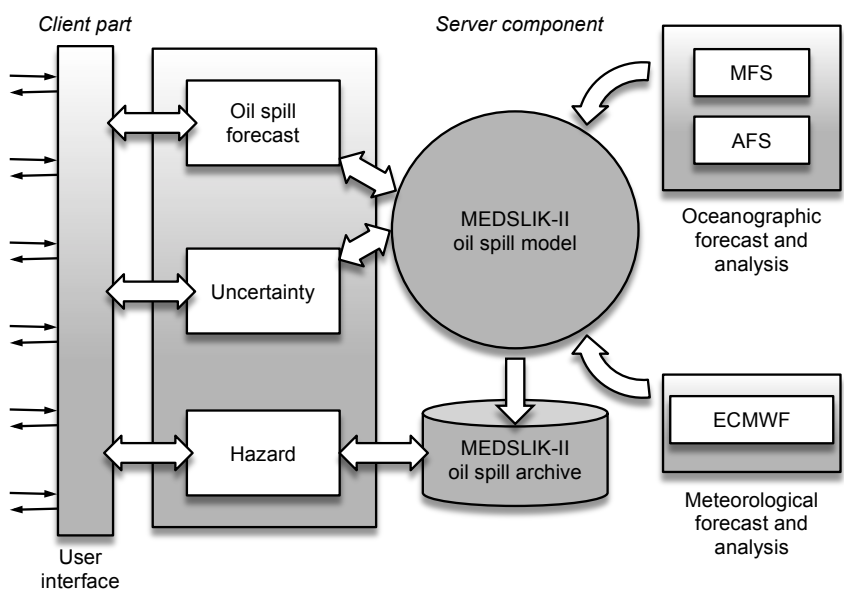

Figure 1. Schematic structure of the WITOIL DSS.

and interpret results. A set of advanced parameters was selected from a full list of MEDSLIK-II parameters published in De Dominicis et al. (2013a). Parameters that can be varied by advanced users are listed in Table 1 . The Stokes drift and a wind drift factor were rated as being of much importance, and were highly discussed in literature (Lehr et al., 2002; De Dominicis et al., 2013a). Horizontal diffusivity is responsible for spatial extension of the oil spill in time. Three parameters that mainly control the weathering processes (evaporation, dispersion, and spreading) can be also modified according to the user's needs. The number of oil particles representing the oil slick can be also changed to control the Lagrangian discretization of the oil slick. Finer discretization results in smoother oil spill patterns, but it requires more computational time.

\subsection{Uncertainty module}

In addition to manually changing the advanced parameters and tracking the differences, WITOIL provides automatic calculation of uncertainties with respect to some initial conditions of the oil spill. Currently, there is not a common approach to the calculation of uncertainties in oil spill modeling. Our methodology is based on a parametric analysis, typical of the atmospheric Lagrangian models (Bergin et al., 1999). Due to a large number of parameters that control the oil movement and transformation in MEDSLIK-II, the number of possible uncertainty scenarios is enormous. WITOIL allows users to evaluate the uncertainty that has arisen from unknown initial conditions online: (1) the starting position, (2) the starting date, and (3) the starting and final dates, which can be varied within user-specified ranges (Table 2). The spread obtained in oil concentrations and represented in probability terms can be interpreted as a measure of uncertainty.

In Scenario I, uncertainty caused by an unknown initial oil spill position is calculated in the case of so-called "cross" 
Table 1. Parameters for advanced user specification.

\begin{tabular}{|c|c|c|c|c|}
\hline No. & Parameter & Default value & Physical meaning & Discussed in reference \\
\hline 1 & Stokes drift & Yes & Turns on the Stokes drift & De Dominicis et al. (2013a) \\
\hline 2 & Direct windage effect & No & Turns off the windage effect & Lehr et al. (2002) \\
\hline 3 & Horizontal diffusivity & $2.0 \mathrm{~m}^{2} \mathrm{~s}^{-1}$ & Controls horizontal turbulent dispersion & De Dominicis et al. (2013a) \\
\hline 4 & Specific evaporation rate & $3.3 \times 10^{-5} \mathrm{~m} \mathrm{~s}^{-1}$ & Controls evaporation of the oil & Mackay et al. (1979) \\
\hline 5 & Specific dispersion rate & $8.0 \times 10^{-6} \mathrm{~s}^{-1}$ & Controls dispersion of the oil by breaking waves & Mackay et al. (1979) \\
\hline 6 & $\begin{array}{l}\text { Specific rate of spreading } \\
\text { of thick slick }\end{array}$ & $150 \mathrm{~s}^{-1}$ & Controls gravity-viscous spreading of the oil & Al-Rabeh et al. (2000) \\
\hline 7 & Number of oil particles & 90000 & Represents Lagrangian discretization of the slick & De Dominicis et al. (2013b) \\
\hline
\end{tabular}

Table 2. Uncertainty scenarios implemented in WITOIL.

\begin{tabular}{lllll}
\hline & $\begin{array}{l}\text { Type of } \\
\text { uncertainty }\end{array}$ & Variable parameters & Range of variation & $\begin{array}{l}\text { Reference } \\
\text { figure }\end{array}$ \\
\hline $\begin{array}{l}\text { Scenario I } \\
\text { Scenario II }\end{array}$ & $\begin{array}{l}\text { Spatial } \\
\text { Temporal }\end{array}$ & $\begin{array}{l}\text { Initial position of the oil spill } \\
\text { Initial date of the oil spill }\end{array}$ & $\begin{array}{l}\text { Uncertainty radius } R \\
\text { Uncertainty interval with respect to } \\
\text { initial date of the spill } t^{0}\end{array}$ & $\begin{array}{l}\text { Fig. } 2 \\
\text { Fig. } 3\end{array}$ \\
Scenario III & Temporal & $\begin{array}{l}\text { Initial and final dates of the } \\
\text { oil spill }\end{array}$ & $\begin{array}{l}\text { Uncertainty interval with respect to } \\
\text { initial date of the spill } t^{0} \text { and final date } t^{*}\end{array}$ & Fig. 4 \\
\hline
\end{tabular}

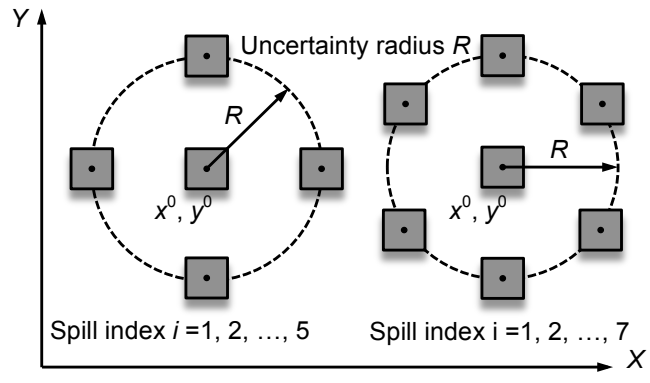

Figure 2. Uncertainty Scenario I with respect to the initial position of the oil spill: cross (left) and hexagon (right) configuration.

and "hexagon" configurations (Fig. 2). For any location of interest $\left(x^{0}, y^{0}\right)$ within the uncertainty radius $R$, the set of spills with the spill indices of $i=1,2, \ldots, N$ is generated. In the case of cross configuration $N=5$. In the case of hexagon configuration $N=7$. All the spills begin at the same time, and they finish synchronously. The final oil concentrations $C^{i}(x, y)$ are aggregated to produce a dimensionless concentration function $H^{i}(x, y)$ defined as

$H^{i}(x, y)=\left\{\begin{array}{ll}1, & C^{i}(x, y)>C_{\mathrm{thr}} \\ 0, & C^{i}(x, y) \leq C_{\mathrm{thr}}\end{array}\right.$,

where $C_{\text {thr }}$ is the threshold oil concentration, specified by users. For the examples described below, we assume that $C_{\mathrm{thr}}=0$. A function $P(x, y)$ expressed in probability terms $(\%)$ can be used as a measure of uncertainty:

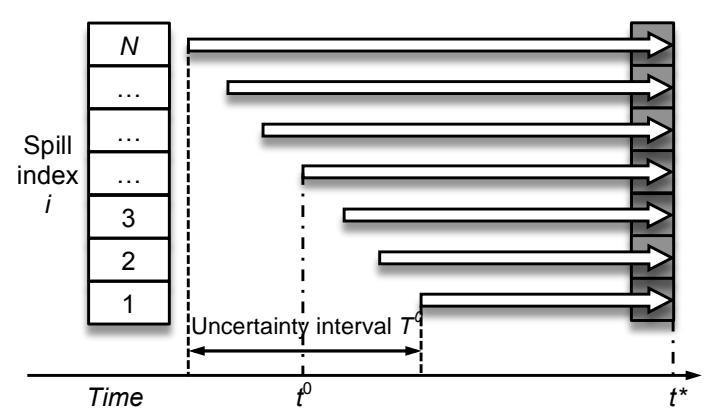

Figure 3. Uncertainty Scenario II with respect to the initial date of the oil spill.

$P(x, y)=100 \% \frac{1}{N} \sum_{i=1}^{N} H^{i}(x, y)$.

Values of $P(x, y)$ range between 0 and $100 \%$, indicating the area where exceeding the threshold concentration is the most probable.

Although the hexagon configuration produces slightly smoother probability patterns than the cross ones, the latter is quicker to calculate.

In Scenario II, uncertainty caused by an unknown starting date of the oil spill is calculated. Hence, for the point of $\left(x^{0}, y^{0}\right)$, a set of oil spills with the spill indices of $i=1,2$, ..., $N$ are generated inside the uncertainty interval $T^{0}$ with respect to the starting date of $t^{0}$. As Fig. 3 indicates, initial dates of these spills are uniformly shifted relative to each 


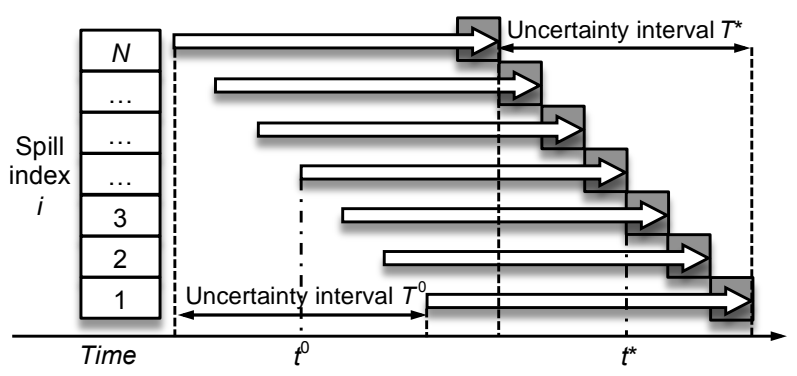

Figure 4. Uncertainty Scenario III with respect to the initial and final dates of the oil spill.

other. At the time of interest $t^{*}$, the final oil concentrations $C^{i}(x, y)$ are aggregated to produce a dimensionless concentration function $H^{i}(x, y)$ due to Eq. (1). In Fig. 3, the gray boxes depict the final oil concentrations. As a result, the probability function $P(x, y)$ calculated by means of Eq. (2) can be interpreted as a measure of the uncertainty regarding the initial date of the oil spill.

In Scenario III, a set of spills is also initiated for the location of $\left(x^{0}, y^{0}\right)$. Apart from variation of the starting date $t^{0}$ within the range of $T^{0}$, the final date of the spillage $t^{*}$ varies within the uncertainty interval $T^{*}$ (Fig. 4). As Fig. 4 shows, both the initial and final dates are shifted relative to each other (in contrast to Scenario II, where the simulation length is frozen for all the spills). To calculate $P(x, y)$, Eqs. (1) and (2) are applied.

\subsection{Hazard module}

The hazard module is tailored to plan a response strategy and increase the level of preparedness prior to real oil spill accidents. Hazard maps represent the MEDSLIK-II outputs statistically based on historical variability of the meteooceanographic data over a long-term period (Liubartseva et al., 2015). This information can also be used for optimization in deployment of spill response equipment and training the response personnel.

Nowadays, accidents on offshore oil and gas facilities are mentioned among risks that might result in severe marine pollution in the Mediterranean Sea. In the present work, we calculated hazard maps in the case of potential accidents on six Adriatic oil platforms: Carmen, Dora, Elisa, Elsa, Gilga, and Ombrina (Fig. 5). To perform the calculations, the oil spill model MEDSLIK-II was coupled with the daily AFS simulations and $6 \mathrm{~h}$ ECMWF analyses over the 7-year time period (2007-2013). On a daily basis, we initiated a typical oil platform leak scenario representing a failure in the oil transportation system (Zhuravel et al., 2013):

- continuous oil spill with duration of $120 \mathrm{~h}$;

- spill rate of $80 \mathrm{th}^{-1}$;

- simulation length of $240 \mathrm{~h}$; and
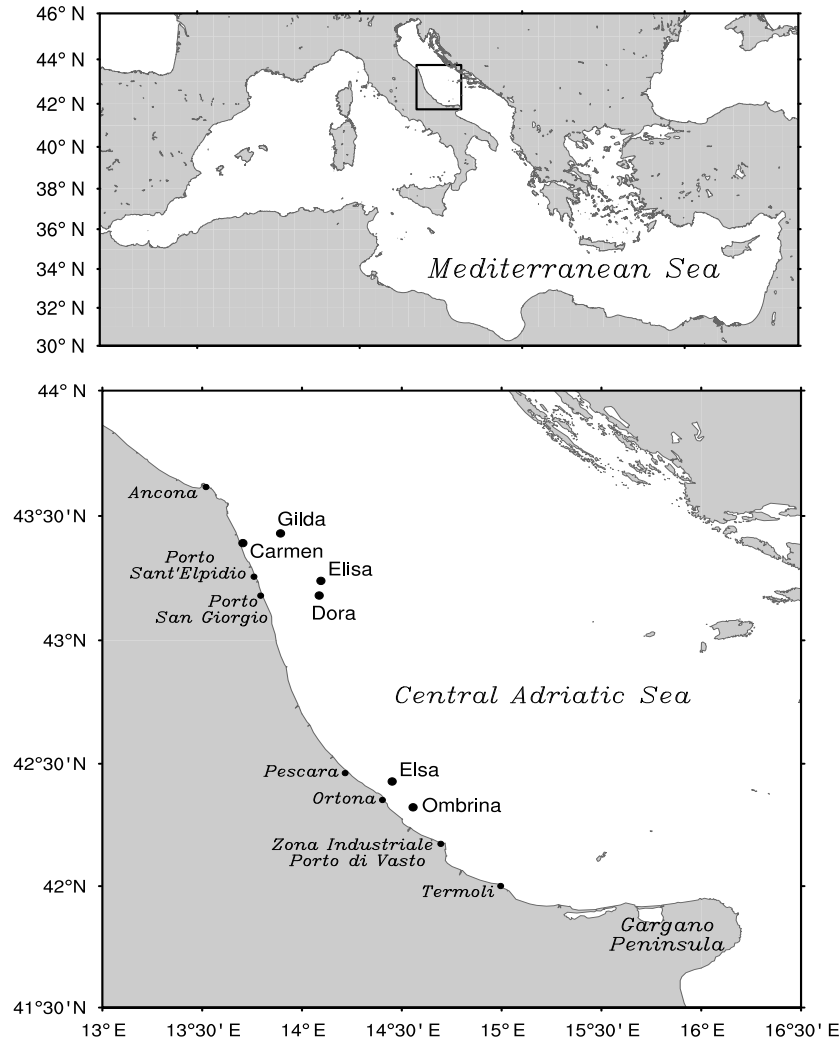

Figure 5. The Adriatic subdomain, where hazards from potential accidents on the oil platforms (Gilda, Carmen, Elisa, Dora, Elsa, and Ombrina) were calculated.

- oil density of $808 \mathrm{~kg} \mathrm{~m}^{-3}$ (API = 17).

Focusing on accidental oil platform leaks, we used the relative high threshold concentrations as follows: $1 \mathrm{t} \mathrm{km}^{-2}$ at the sea surface, $0.1 \mathrm{t} \mathrm{km}^{-1}$ on the coastline, and $1 \mathrm{t} \mathrm{km}^{-2}$ for the dispersed oil fraction (French McCay et al., 2004).

\section{Results}

A service-oriented approach plays a key role in the WITOIL DSS development. The eight-language graphical user interface is supplied with a great variety of user services, including help and support, tooltips, and a video tutorial ${ }^{4}$, etc. The system is designed to meet the real-time requirements in terms of performance and dynamic service delivery. Comprehensive computational resources incorporated in WITOIL DSS and network bandwidth efficiently support the multiuser regime and the independent processing of user requests.

\subsection{Oil spill forecast}

An example of using the oil spill forecasting module is shown in Fig. 6. Information about a hypothetical oil spill

\footnotetext{
${ }^{4}$ https://www.youtube.com/watch?v=qj_GokYy8MU
} 


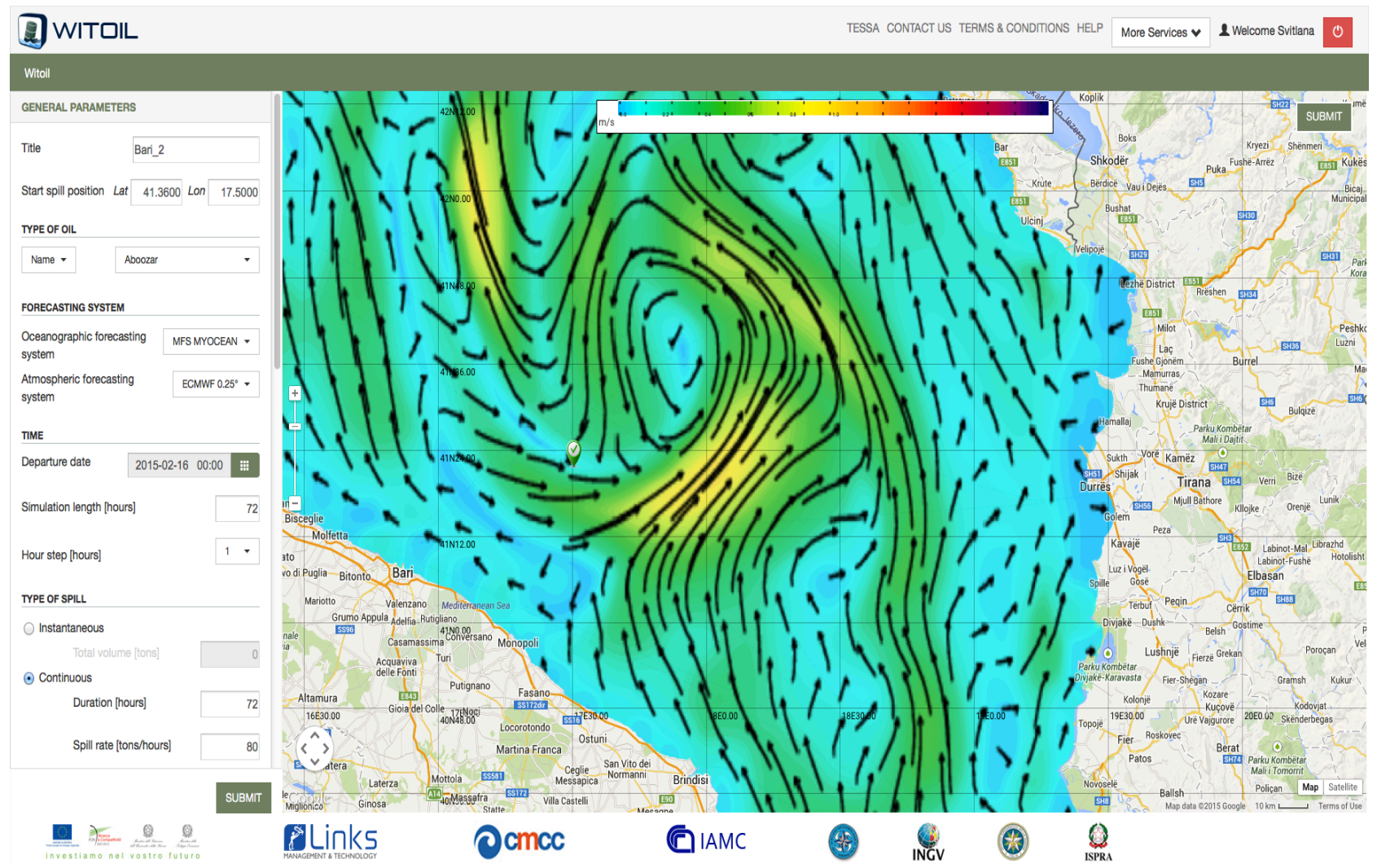

Figure 6. User interface of the WITOIL decision support system.

located in the southern Adriatic Sea $\left(41.36^{\circ} \mathrm{N}, 17.50^{\circ} \mathrm{E}\right)$, near the Ancona (Italy) to Igoumenitsa (Greece) shipping lane, was put into the WITOIL DSS. The accident started on 16 February 2015 at midnight. It was a continuous spill with a rate of $80 \mathrm{th}^{-1}$ and expected duration of $72 \mathrm{~h}$. The oil type of Aboozar with an American Petroleum Institute (API) gravity of 26.96 and density of $893 \mathrm{~kg} \mathrm{~m}^{-3}$ was spilled. An oil spill forecast was carried out by means of the ECMWF and MFS meteo-oceanographic datasets. The corresponding field of sea surface currents, underlying the area of the accident, indicated that initially, the spill was located in the region of relatively weak currents at the periphery of the South Adriatic Gyre (Artegiani et al., 1997). The sea surface current field presented in Fig. 6 is a product of MFS visualized by means of SeaConditions ${ }^{5}$, one of the services in the TESSA project portfolio (Lecci et al., 2015).

Following the user's settings, WITOIL produced the hourly snapshots of oil concentration at the surface and on the coastline, and their animation. Recent calculations can be automatically saved at the server side and quickly restored afterwards. In Fig. 7, the last snapshot of the oil spill forecast is presented. In $72 \mathrm{~h}$ after the accident, an elongated oil spill moved under the influence of the local currents and the Stokes drift. Wind speed vector with a magnitude of about

\footnotetext{
${ }^{5}$ http://www.sea-conditions.com
}

$4 \mathrm{~m} \mathrm{~s}^{-1}$ in the slick mass center is depicted in Fig. 7. Local currents were rather weak and moderate, and they demonstrated cyclonic vorticity in the slick area. It is clearly evident that the South Adriatic Gyre directly influenced the transport and shape of the spill. The oil concentration at the sea surface reached $70 \mathrm{t} \mathrm{km}^{-2}$, while the coastline of Italy remained pristine.

\subsection{Uncertainty estimations}

After receiving the forecast of the oil spill movement, uncertainty of this forecast can be obtained online. First of all, uncertainty with respect to the starting oil spill position was calculated in the framework of Scenario I (Fig. 2) described above. An uncertainty radius of $R=2$ nautical miles or about $2.3 \mathrm{~km}$ was chosen as an example. As Fig. 8 indicates, south and southeast directions at a distance of about $9 \mathrm{~km}$ were found to be the most probable (>75\%) for the oil location in $72 \mathrm{~h}$ after the accident. Besides, there was a small but nonzero probability (about 20\%) that oil went west of the starting position. Both cross and hexagon configurations gave very similar probability distributions.

An example of the uncertainty evaluation with respect to the starting date of oil spill is presented in Fig. 9. In Scenario II (Fig. 3), seven spills were run inside the uncertainty interval of $T^{0}=36 \mathrm{~h}$. The spills were shifted by $6 \mathrm{~h}$ rela- 


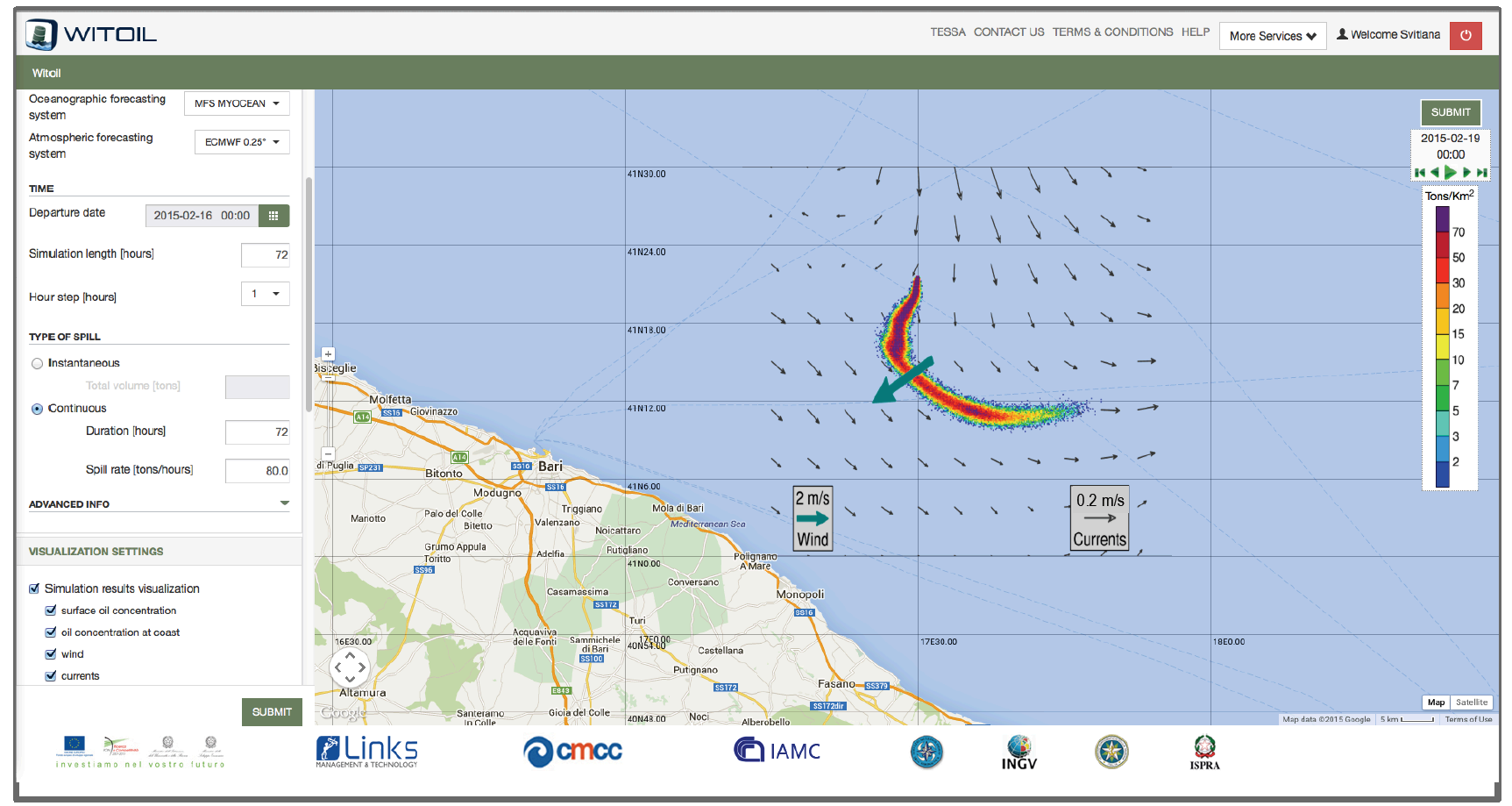

Figure 7. Result of the oil spill forecast in $72 \mathrm{~h}$ after the accident.
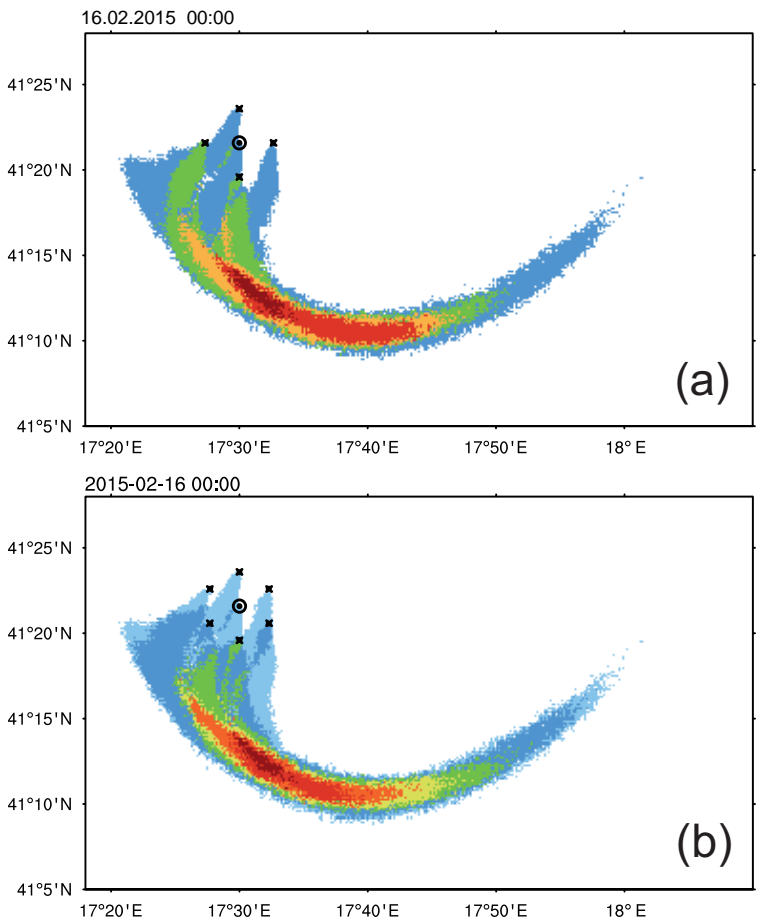

Figure 8. Uncertainty of the oil spill forecast with respect to the starting location of the oil spill (Scenario I): in cross (a) and hexagon (b) configuration.

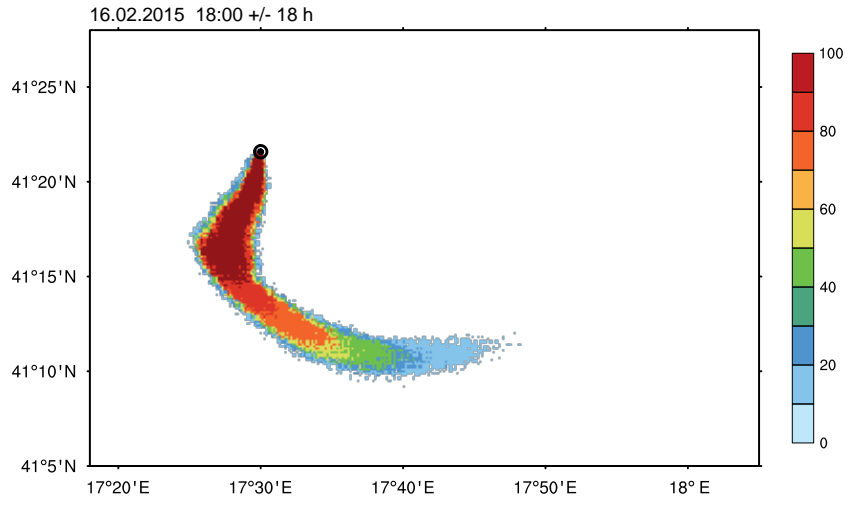

Figure 9. Uncertainty of the oil spill forecast with respect to the starting date of the oil spill (Scenario II).

tive to each other. Probability distribution indicated a narrow comet-shaped band with the highest values at the distance of 4-9 km southwest and southeast of the starting position. In Fig. 9, the probability spread was insignificant, which allowed the conclusion to be established that, for variations of the starting spill time in the interval of $36 \mathrm{~h}$, uncertainty in the oil spill forecast was not high.

Seven spills were also initiated inside the uncertainty intervals of $T^{0}=T^{*}=36 \mathrm{~h}$ in Scenario III (Fig. 4). The spills were shifted by $6 \mathrm{~h}$. In contrast to Scenario II, the obtained probability distribution demonstrated more significant spatial spread. As Fig. 10 shows, the most probable (>71\%) 


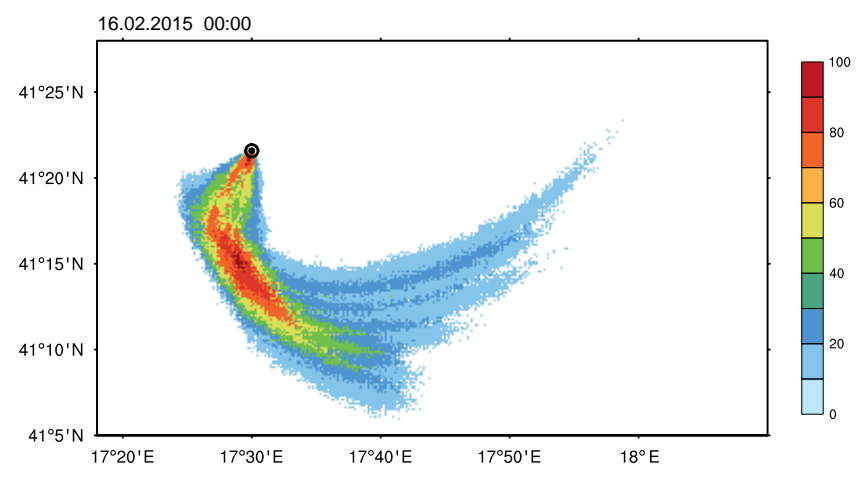

Figure 10. Uncertainty of the oil spill forecast with respect to the starting and final dates of the oil spill (Scenario III).

direction was southwest, while the southeast one was less probable (about $14 \%$ ). It can be concluded that, in the aforementioned cases, the main forecast uncertainty arose from the degree of the South Adriatic Gyre influence.

\subsection{Hazards from the oil platforms}

To calculate hazards from potential accidents on six Adriatic oil platforms (Gilda, Carmen, Elisa, Dora, Elsa, and Ombrina), over 15000 MEDSLIK-II runs were carried out for the 2007-2013 time period. In general, more than 1500 monthly hazard maps were produced, including hazard maps of the sea surface and the coastline and maps of the dispersed oil fraction. Additionally, more than 400 averaged hazard maps were calculated: yearly, seasonally averaged maps and monthly climatology maps. Currently, the hazard module has not yet been incorporated in the WITOIL DSS. However, a further version of WITOIL will be able to sort and visualize all the precalculated hazard maps.

Two oil platforms, Carmen and Ombrina, were found to be the most hazardous to the Italian coastal zone. Monthly averaged maps (Fig. 11) demonstrated the most significant spatial variability of hazards.

As Fig. 11a, d indicate, the shape of the highest surface hazard area followed the climatological shape of the Western Adriatic Coastal Current (Artegiani et al., 1997; Oddo et al., 2005). The same feature was found on the hazard maps for the dispersed fraction of the oil, but for a lower level of hazards (Fig. 11c, f). For both platforms, the maximum magnitude of hazard on the coastline tended to exceed the values at the sea surface and in the water column. It means that in the case of accidents on the oil platforms, the most hazardous impact is expected on the Italian coastline.

In the case of Carmen, hazards reached the maximum values of more than 0.8 on the coastline from Porto Sant'Elpidio to Porto San Giorgio (Fig. 11b). Sea surface hazard distributions revealed high hazards $(>0.5)$ near Porto Sant'Elpidio, while a narrow area of relatively moderate hazards $(>0.3)$ extended up to Pescara (Fig. 11a). Hazards from the dis- persed oil fraction were rather low $(0.05-0.25)$ but due to a long-term cumulative effect, some impact on fishery stocks near Pescara and Ortona (Fig. 11c) might be expected.

Possible accidents on Ombrina led to high coastline hazards $(>0.8)$ in Zona Industriale Porto di Vasto and Termoli, covering the northern coast of the Gargano Peninsula (Fig. 11e), where Gargano National Park is situated. Additionally, the coastline of the Tremiti Islands $(16 \mathrm{~km}$ north of the Gargano Peninsula, $42.12^{\circ} \mathrm{N}, 15.51^{\circ} \mathrm{E}$ ) also indicated significant hazards $(0.5-0.7)$. Sea surface hazards showed high values $(>0.5)$ in the area between the platform and Termoli (Fig. 11d). Hazards from the dispersed oil were rather low (0.05-0.25) but they was be able to impact the diving sites near the Tremiti archipelago (Fig. 11f).

\subsection{Mobile application for Android}

A simplified version of the WITOIL DSS ${ }^{6}$ is developed for Android to share information during field response operations (Fig. 12). A user-friendly interface incorporates the necessary set of general parameters in order to obtain the oil spill forecast and make decisions and disseminate them among the members of a response team on a near-real-time basis. In addition, users may take advantage of unified access to all the mobile applications of TESSA products and services. For example, a mobile version of SeaConditions provides users with a single point of access to meteo-marine forecasts (surface currents, sea surface temperature, significant wave height and direction, wave period and direction, air temperature, surface pressure, precipitation, cloud coverage, wind speed) and remote sensing observations (chlorophyll $a$ concentration and water transparency). It is planned that a WITOIL application for iOS is developed for the next version of the system.

\section{Conclusions}

The WITOIL decision support system as an innovative webbased tool has been implemented in the framework of the TESSA project. The system is designed to support emergency organization in the case of oil spill accidents in the Mediterranean Sea.

The system incorporates three modules, namely oil spill forecast, uncertainty evaluation, and hazard assessment. WITOIL is based on MEDSLIK-II oil spill code (De Dominicis et al., 2013a, b) coupled with the operational oceanographic and atmospheric services. The system allows representation of the model predictions and geospatial data on different types of devices: personal computers, tablets, mobile phones, etc.

The oil spill forecast module focuses on performing reliable and accurate predictions of oil spill trajectory and fate,

\footnotetext{
${ }^{6}$ https://play.google.com/store/apps/details?id=it.cmcc.witoil
} 

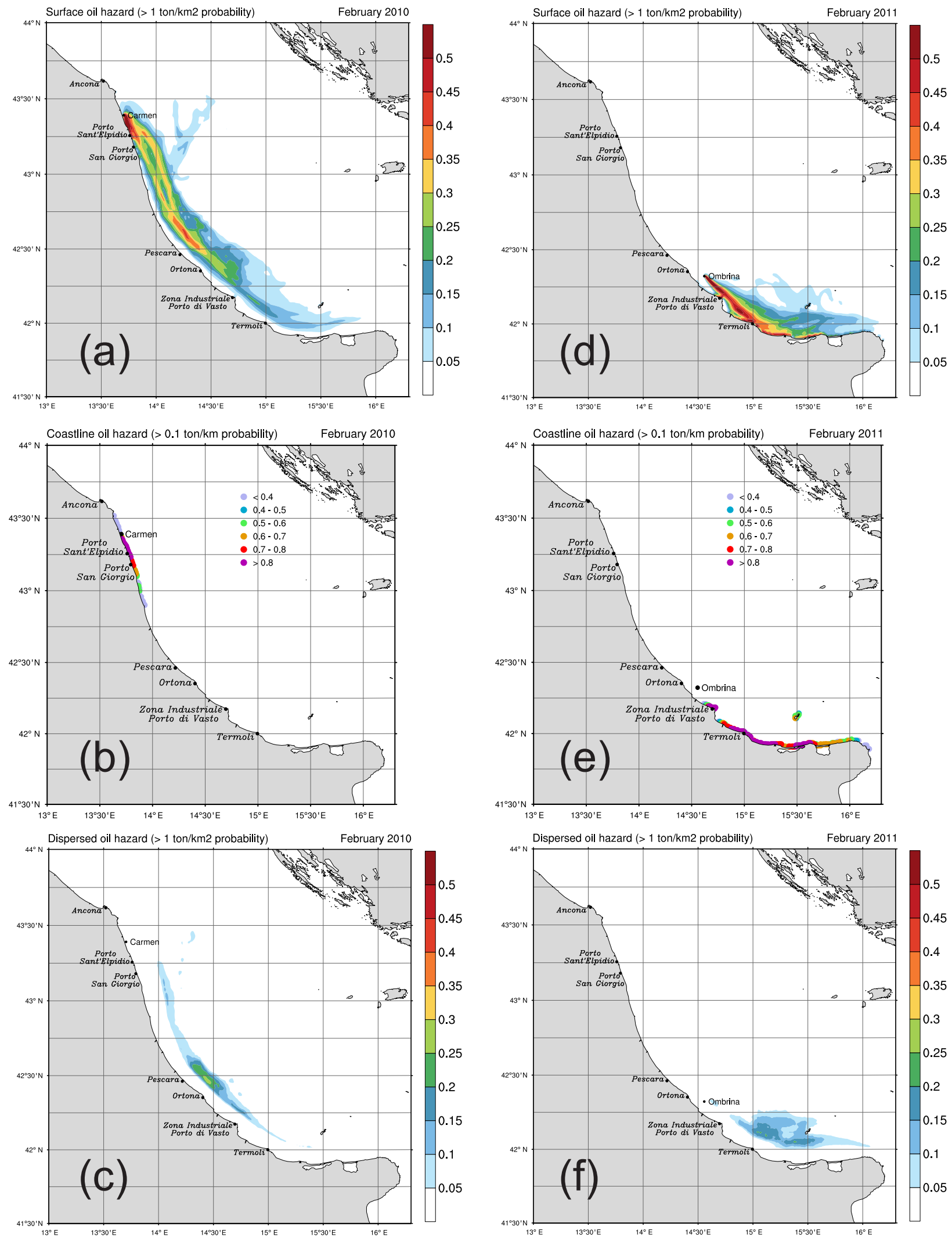

Figure 11. Monthly averaged hazard maps for the Carmen oil platform in February 2010 (left panel): at the sea surface (a), on the coastline (b), for the dispersed oil (c); and Ombrina oil platform in February 2011 (right panel): at the sea surface (d), on the coastline (e), for the dispersed oil (f). 


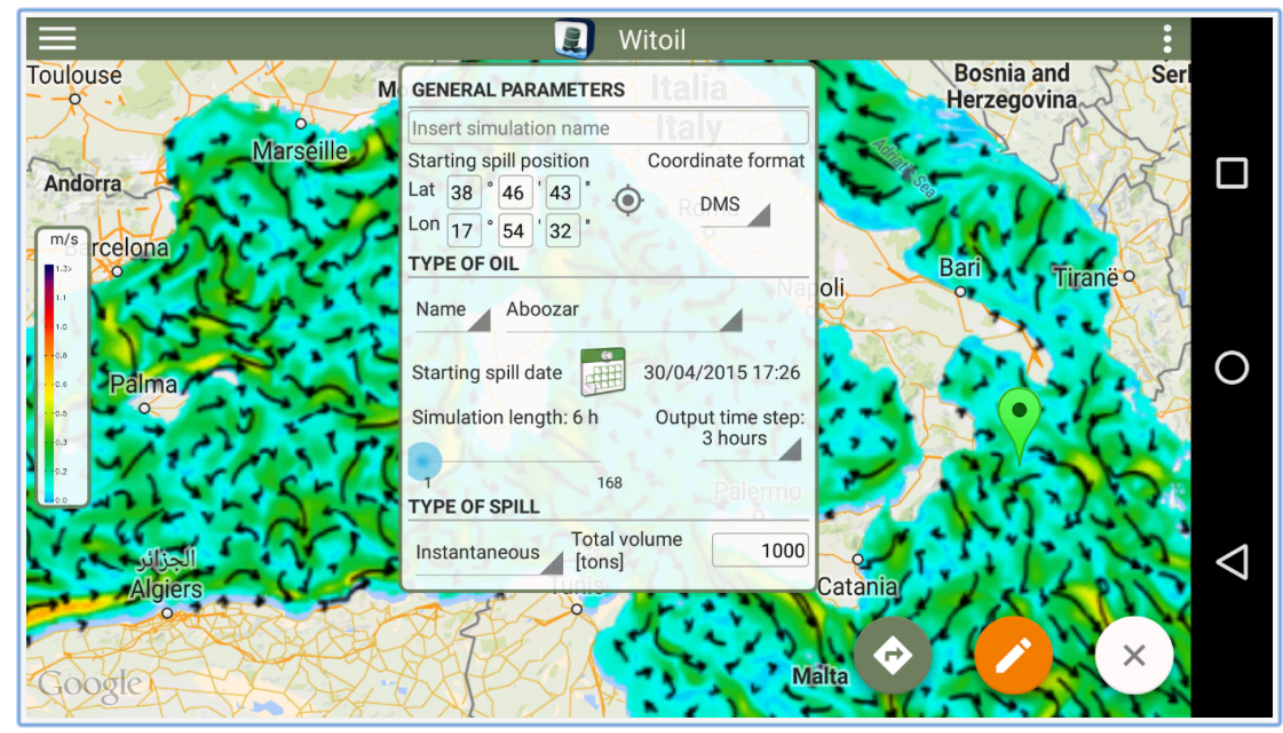

Figure 12. General view of the WITOIL application for Android.

which can be routinely updated based on the operational forecasting chain.

The uncertainty module allows users to evaluate variability of the forecast caused by uncertain data on the initial oil spill conditions.

The hazard module identifies the impact areas (at the sea surface, on the coastline, and in the water column) in the case of possible oil spill accidents, based on the Lagrangian modeling of the oil drift driven by historical meteooceanographic datasets. Calculation of hazards requires significant computational resources. WITOIL will be used for the visualization of precalculated hazard maps.

Functionality of the system has been demonstrated by the example of a hypothetical oil spill in the southern Adriatic Sea in February 2015. The $72 \mathrm{~h}$ forecast indicated initial southwestward movement of the oil with subsequent southeastward transport by the South Adriatic Gyre. However, uncertainty analysis with respect to the initial location and date of the oil spill showed that the oil spill trajectory could shift eastward or westward depending on the influence of the South Adriatic Gyre.

Capability of the hazard module has been illustrated by hazard maps for six Adriatic oil platforms in the case of potential accidents due to failure in the oil transportation system. Carmen and Ombrina oil platforms were found to be the most hazardous to the Italian coastal zone. Distinctive hot spots were indicated along the coast from Porto Sant'Elpidio to Porto San Giorgio, in Zona Industriale Porto di Vasto and Termoli, as well on the northern coastline of the Gargano Peninsula.

The WITOIL application for Android has been implemented to share the oil spill forecast during field response activities.
In the current version of the WITOIL DDS, the oil forecasting module is the most advanced one due to the highest priority. Its development is based on all the previous experience of MEDSLIK-II applications to real cases (De Dominicis et al., 2013b, 2014; Coppini et al., 2011; Samaras et al., 2014; Alves et al., 2015). Further implementation of the forecasting module will be related to the improvement of integration with the other high-resolution meteo-oceanographic models and user services. To our knowledge, the developed uncertainty module regarding the initial oil spill conditions is unique. Therefore, users' feedback is needed for the further implementation of this module. Future progress in the hazard module can be associated with obtaining the MEDSLIK-II oil spill archive in order to include additional oil spill sources and cover the whole of the Mediterranean Basin.

\section{Data availability}

The underlying operational oceanography datasets are available via the Copernicus Marine Environment Monitoring Service at http://marine. copernicus.eu/services-portfolio/access-to-products/ ?option=com_csw\&task=results\&simplesearch= ok\&advancedsearch-geographical_area[]= advancedsearch-geographical_area-mediterranean-sea (Istituto Nazionale di Geofisica e Vulcanologia, 2016a). The MEDSLIK-II model code and the accompanied documentation are freely available in the Download section at http://medslikii.bo.ingv.it (Istituto Nazionale di Geofisica e Vulcanologia, 2016b). All the uncertainty and hazard algorithms used are transparent either in the present paper or via the references cited. 
Acknowledgements. This work was performed in the framework of the TESSA project (Sviluppo di TEcnologie per la Situational Sea Awareness) supported by PON (Ricerca \& Competitività 20072013) co-funded by UE (Fondo Europeo di sviluppo regionale), MIUR (Ministero Italiano dell'Università e della Ricerca), and MSE (Ministero dello Sviluppo Economico). The study was carried out using EU Copernicus Marine Service information. The authors thank Angela Cocozza for performing hazard calculations for the Ombrina oil platform.

Edited by: A. Olita

Reviewed by: two anonymous referees

\section{References}

Al-Rabeh, A., Lardner, R., and Gunay, N.: Gulfspill version 2.0: A software package for oil spills in the Arabian Gulf, Environ. Modell. Softw., 15, 425-442, doi:10.1016/S13648152(00)00013-X, 2000.

Alves, T., Kokinou, E., Zodiatis, G., Lardner, R., Panagiotakis, C., and Radhakrishnan, H.: Modelling of oil spills in confined maritime basins: The case for early response in the Eastern Mediterranean Sea, Environ. Pollut., 206, 390-399, doi:10.1016/j.envpol.2015.07.042, 2015.

Ambjorn, C.: SeatrackWeb, forecasts of oil spills, a new version, Environ. Res. Eng. Manage., 3, 60-66, doi:10.1109/BALTIC.2006.7266187, 2007.

Anderson, S., Uiboupin, R., Verjovkina, S., and Raudsepp, U.: SAR imagery and SeatrackWeb as decision making tools for illegal oil spill combating - a case study, in: 4th IEEE/OES US/EU Baltic International Symposium, Riga, Latvia, 25-27 August 2010, 16, doi:10.1109/BALTIC.2010.5621629, 2010.

Artegiani, A., Bregant, D., Paschini, E., Pinardi, N., Raicich, F., and Russo, A.: The Adriatic Sea general circulation, Part II: baroclinic circulation structure, J. Phys. Oceanogr., 27, 1515-1532, doi:10.1175/1520-0485(1997)027<1515:TASGCP>2.0.CO;2, 1997.

Bergin, M., Noblet, G., Petrini, K., Dhieux, J., Milford, J., and Harley, R.: Formal uncertainty analysis of a Lagrangian photochemical air pollution model, Environ. Sci. Technol., 33, 11161126, doi:10.1021/es980749y, 1999.

Carracedo, P., Torres-Lopez, S., Barreiro, M., Montero, P., Balseiro, C., Penabad, E., Leitao, P., and Perez-Munuzuri, V.: Improvement of pollutant drift forecast system applied to the Prestige oil spills in Galicia Coast (NW of Spain): Development of an operational system, Mar. Pollut. Bull., 53, 350-360, doi:10.1016/j.marpolbul.2005.11.014, 2006.

Coppini, G., De Dominicis, M., Zodiatis, G., Lardner, R., Pinardi, N., Santoleri, R., Colella, S., Bignami, F., Hayes, D., Soloviev, D., Georgiou, G., and Kallos, G.: Hindcast of oil spill pollution during the Lebanon Crisis, July-August 2006, Mar. Pollut. Bull., 62, 140-153, doi:10.1016/j.marpolbul.2010.08.021, 2011.

Daniel, P.: Operational forecasting of oil spill drift at Meteo-France, Spill Sci. Technol. B., 3, 53-64, 1996.

De Dominicis, M., Pinardi, N., Zodiatis, G., and Lardner, R.: MEDSLIK-II, a Lagrangian marine surface oil spill model for short-term forecasting - Part 1: Theory, Geosci. Model Dev., 6, 1851-1869, doi:10.5194/gmd-6-1851-2013, 2013a.
De Dominicis, M., Pinardi, N., Zodiatis, G., and Archetti, R.: MEDSLIK-II, a Lagrangian marine surface oil spill model for short-term forecasting - Part 2: Numerical simulations and validations, Geosci. Model Dev., 6, 1871-1888, doi:10.5194/gmd-61871-2013, 2013b.

De Dominicis, M., Falchetti, S., Trotta, F., Pinardi, N., Giacomelli, L., Napolitano, E., Fazioli, L., Sorgente, R., Haley, P., Lermusiaux, P., Martins, F., and Cocco, M.: A relocatable ocean model in support of environmental emergencies - the Costa Concordia emergency case, Ocean Dynam., 64, 667-688, doi:10.1007/s10236-014-0705-x, 2014.

De Dominicis, M., Bruciaferri, D., Gerin, R., Pinardi, N., Poulain, P.M., Garreau, P., Zodiatis, G., Perivoliotis, L., Fazioli, L., Sorgente, R., and Manganiello, C.: A multi-model assessment of the impact of currents, waves and wind in modelling surface drifters and oil spill, Deep-Sea Res. Pt. II, doi:10.1016/j.dsr2.2016.04.002, in press, 2016.

Dobricic, S. and Pinardi, N.: An oceanographic three-dimensional variational data assimilation scheme, Ocean Model., 22, 89-105, doi:10.1016/j.ocemod.2008.01.004, 2008.

ERMA: Environmental Response Management Application. Web application. Technical Information, in: National Oceanic and Atmospheric Administration, available atL http://response.restoration.noaa.gov/maps-and-spatial-data/ environmental-response-management-application-erma (last access: 26 August 2016), 2014.

Fernandes, R., Neves, R., and Viegas, C.: Probabilities of oil exceeding thresholds of concern: examples from an evaluation for Florida Power and Light, in: AMOP 36 Technical Seminar, 4 6 June 2013, Halifax, Nova Scotia, Canada, 326-353, 2013.

French McCay, D., Rowe, J., Whittier, N., Sankaranarayanan, S., and Etkin, D. S.: Estimation of potential impacts and natural resource damages of oil, J. Hazard. Mater., 107, 11-25, doi:10.1016/j.jhazmat.2003.11.013, 2004

Hasselmann, K., Barnett, T., Bouws, E., Carlson, H., Cartwright, D., Enke, K., Ewing, J., Gienapp, H., Hasselmann, D., Kruseman, P., Meerburg, A., Mller, P., Olbers, D., Richter, K., Sell, W., and Walden, H.: Measurements of wave growth and swell decay during the Joint North Sea Wave Project (JONSWAP), Ergänzungsheft zur Deutschen Hydrographischen Zeitschrift Reihe, Deutsches Hydrographisches Institut, Hamburg, Germany, A8-12, 1973.

Istituto Nazionale di Geofisica e Vulcanologia, Italy: Mediterranean sea physics analysis and forecast, available at: http://marine.copernicus.eu/ services-portfolio/access-to-products/?option=com_csw\&task= results\&simplesearch=ok\&advancedsearch-geographical_ area[]=advancedsearch-geographical_area-mediterranean-sea, last access: 12 August 2016a.

Istituto Nazionale di Geofisica e Vulcanologia, Italy: MEDSLIKII, available at: http://medslikii.bo.ingv.it, last access: 24 August $2016 b$.

Jensen, J., Ramsey, E., Holmes, J., Michel, J., Savitsky, B., and Davis, B.: Environmental sensitivity index (ESI) mapping for oil spills using remote sensing and geographic information system technology, Geograph. Inf. Sys, 4, 181-201, doi:10.1080/02693799008941539, 1990.

Lecci, R., Coppini, G., Cretì, S., Turrisi, G., D’Anca, A., Palazzo, C., Aloisio, G., Fiore, S., Bonaduce, A., Mannarini, G., Kumkar, 
Y., Ciliberti, S., Federico, I., Agostini, P., Bonarelli, R., Martinelli, S., Marra, P., Scalas, M., Tedesco, L., Rollo, D., Cavallo, A., Tumolo, A., Monacizzo, T., Spagnulo, M., Pinardi, N., Fazioli, L., Olita, A., Cucco, A., Sorgente, R., Tonani, M., and Drudi, M.: SeaConditions: present and future sea conditions for safer navigation, in: OCEANS-2015, 18-21 May 2015, Genoa, Italy, 1-6, available at: http://www.sea-conditions.com (last access: 12 May 2016), 2015.

Lehr, W., Jones, R., Evans, M., and Simecek-Beatty, D.: Revisions of the ADIOS oil spill model, Environ. Modell. Softw., 17, 191199, 2002.

Liubartseva, S., De Dominicis, M., Oddo, P., Coppini, G., Pinardi, N., and Greggio, N.: Oil spill hazard from dispersal of oil along shipping lanes in the Southern Adriatic and Northern Ionian Seas, Mar. Pollut. Bull., 90, 259-272, doi:10.1016/j.marpolbul.2014.10.039, 2015.

Mackay, D., Buist, I., Mascarenhas, R., and Paterson, S.: Oil spill processes and models, Report to Research and Development Division, Environment Emergency Branch, Environmental Impact Control Directorate, Environmental Protection Service, Environment Canada, Ottawa, Canada, 1979.

Muskat, J.: The evolution of applied geographic information systems for oil spill response in California: Rapid data dissemination for informed decision making, in: International Oil Spill Conference (IOSC), 5-8 May, 2014, Savannah, Georgia, USA, 1583-1595, 2014.

Nittis, K., Perivoliotis, L., Korres, G., Tziavos, C., and Thanos, I.: Operational monitoring and forecasting for marine environmental applications in the Aegean Sea, Environ. Modell. Softw., 21, 243-257, doi:10.1016/j.envsoft.2004.04.023, 2006.

Oddo, P., Pinardi, N., and Zavatarelli, M.: A numerical study of the interannual variability of the Adriatic Sea (2000-2002), Sci. Total Environ., 353, 39-56, doi:10.1016/j.scitotenv.2005.09.061, 2005.

Oddo, P., Adani, M., Pinardi, N., Fratianni, C., Tonani, M., and Pettenuzzo, D.: A nested Atlantic-Mediterranean Sea general circulation model for operational forecasting, Ocean Sci., 5, 461-473, doi:10.5194/os-5-461-2009, 2009.

Pinardi, N., Allen, I., Demirov, E., De Mey, P., Korres, G., Lascaratos, A., Le Traon, P.-Y., Maillard, C., Manzella, G., and Tziavos, C.: The Mediterranean ocean forecasting system: first phase of implementation (1998-2001), Ann. Geophys., 21, 3-20, doi:10.5194/angeo-21-3-2003, 2003.
Reed, M., Aamo, O., and Daling, P.: Quantitative analysis of alternate oil spill response strategies using OSCAR, Spill Sci. Technol. B., 2, 67-74, doi:10.1016/1353-2561(95)00020-5, 1995.

Samaras, A. G., De Dominicis, M., Archetti, R., Lamberti, A., and Pinardi, N.: Towards improving the representation of beaching in oil spill models: A case study, Mar. Pollut. Bull., 88, 91-101, doi:10.1016/j.marpolbul.2014.09.019, 2014.

Sebastiao, P. and Guedes Soares, C.: Uncertainty in predictions of oil spill trajectories in open sea, Ocean Eng., 34, 576-584, doi:10.1016/j.oceaneng.2006.01.014, 2007.

Tonani, M., Pinardi, N., Dobricic, S., Pujol, I., and Fratianni, C.: A high-resolution free-surface model of the Mediterranean Sea, Ocean Sci., 4, 1-14, doi:10.5194/os-4-1-2008, 2008.

Wirtz, K. and Liu, X.: Integrating economy, ecology and uncertainty in an oil-spill DSS: The Prestige accident in Spain, 2002, Estuar. Coast. Shelf S., 70, 525-532, doi:10.1016/j.ecss.2006.06.016, 2006.

$\mathrm{Xu}$, H., Chen, J., Wang, S., and Liu, Y.: Oil spill forecast model based on uncertainty analysis: A case study of Dalian oil spill, Estuar. Coast. Shelf S., 54, 206-212, doi:10.1016/j.oceaneng.2012.07.019, 2012.

Zelenke, B., O’Connor, C., Barker, C., Beegle-Krause, C. J., and Eclipse, L.: General NOAA Operational Modeling Environment (GNOME) Technical Documentation, U.S. Dept. of Commerce, NOAA Technical Memorandum NOS OR and R 40. Seattle, WA, USA: Emergency Response Division, NOAA, 2012.

Zhuravel, V., Zhuravel, I., Zatsepa, S., Zelenko, A., Ivchenko, A., Kulakov, M., Lobov, A., Popov, S., Resnyansky, Y., Svetov, S., Smolyanitsky, V., Solbakov, V., and Stanovoy, V.: Modeling of potential oil spill behavior when operating Prirazlomnaya OIFP. Assessment of possible oil spill emergency response. Research report, RGC Risk Informatics, Moscow, Russia, 2013.

Zodiatis, G., Lardner, R., Hayes, D. R., Georgiou, G., Sofianos, S., Skliris, N., and Lascaratos, A.: Operational ocean forecasting in the Eastern Mediterranean: implementation and evaluation, Ocean Sci., 4, 31-47, doi:10.5194/os-4-31-2008, 2008. 